\title{
Cortico-cerebellar functional connectivity and sequencing of movements in schizophrenia
}

Tomas Kasparek ${ }^{1,2 *}$, Jitka Rehulova ${ }^{1,2}$, Milos Kerkovsky $^{3}$, Andrea Sprlakova $^{3}$, Marek Mechl $^{3}$ and Michal Mikl ${ }^{4}$

\begin{abstract}
Background: Abnormal execution of several movements in a sequence is a frequent finding in schizophrenia. Successful performance of such motor acts requires correct integration of cortico-subcortical processes, particularly those related to cerebellar functions. Abnormal connectivity between cortical and cerebellar regions with resulting cognitive dysmetria has been proposed as the core dysfunction behind many signs and symptoms of schizophrenia. The aim of the present study was to assess if these proposed abnormalities in connectivity are a unifying feature of schizophrenia, or, rather, reflect a specific symptom domain of a heterogeneous disease. We predicted that abnormal functional connectivity between the motor cortex and cerebellum would be linked with abnormal performance of movement sequencing.
\end{abstract}

Methods: We examined 24 schizophrenia patients $(\mathrm{SCH})$ and 24 age-, sex-, and handedness-matched healthy controls (HC) using fMRI during a modified finger-tapping task. The ability to perform movement sequencing was tested using the Neurological Evaluation Scale (NES). The subjects were categorized into two groups, with (SQ+) and without (SQ-) movement sequencing abnormalities, according to the NES-SQ score. The effects of diagnosis and movement sequencing abnormalities on the functional connectivity parameters between the motor cortex and cerebellum (MC-CRBL) and the supplementary motor cortex and cerebellum (SMA-CRBL) activated during the motor task were analyzed.

Results: We found no effect of diagnosis on the functional connectivity measures. There was, however, a significant effect on the SQ group: SQ + patients showed a lower level of MC-CRBL connectivity than SQ- patients and healthy controls. Moreover, the level of MC-CRBL and SMA-CRBL negatively correlated with the magnitude of NES-SQ abnormalities, but with no other NES domain.

Conclusions: Abnormal cortico-cerebellar functional connectivity during the execution of a motor task is linked with movement sequencing abnormalities in schizophrenia, but not with the diagnosis of schizophrenia per se. It seems that specific patterns of inter-regional connectivity are linked with corresponding signs and symptoms of clinically heterogeneous conditions such as schizophrenia.

Keywords: Schizophrenia, Motor cortex, Cerebellum, Connectivity, Movement sequencing, Neurological soft signs

\section{Background}

Schizophrenia is a heterogeneous mental illness with a variable clinical manifestation. Individual patients present with a variable pattern of symptoms, including abnormalities of higher integrative functions, such as perception, thinking, cognition, and, quite frequently, abnormalities of motor functioning. Abnormalities of

\footnotetext{
* Correspondence: tomas.kasparek@centrum.cz

'Department of Psychiatry, University Hospital Brno and Masaryk University, Jihlavska 20, 62500 Brno, Czech Republic

Full list of author information is available at the end of the article
}

the motor system in schizophrenia are related to the minor neurological changes that are traditionally referred to as neurological soft signs (NSS). They include problems with sequencing of movements (i.e., performance of several movements one by one in turn), and coordination of movements (i.e., performance of several movements simultaneously in time). Dysfunction of movement sequencing seems to be the prominent motor symptom in schizophrenia [1]. NSS are independent of the extrapyramidal adverse effects of antipsychotic drugs; i.e., they are not a result of the treatment

\section{Biomed Central}


$[2,3]$, but a reflection of the basic neurobiology of the illness.

At the level of brain physiology, schizophrenia is linked with abnormalities of brain connectivity. Inefficient or misleading communication between functional brain areas has been postulated to be the core dysfunction behind the clinical manifestation of the illness. Friston and Frith stressed the importance of corticocortical connectivity-fronto-temporal connectivity- - and coined the term 'dysconnection' [4]. Later, Andreasen et al. formed the theory of cognitive dysmetria as a basic cognitive dysfunction that arises from abnormal coordination in loops formed by the cortex, thalamus, and cerebellum, with a special focus on cerebellar functions in the fine timing of motor and cognitive events [5]. Abnormal connectivity in cortico-cerebellar loops would lead to disorganization of complex neurophysiological and mental processes, as seen in schizophrenia. Although a substantial body of evidence for abnormal brain functional connectivity in schizophrenia exists $[6,7]$, no overall specific pattern of connectivity changes in schizophrenia has emerged. The heterogeneity of the findings reflects the clinical heterogeneity of the illness, where various phenotypes stem from different patterns of connectivity changes.

Although an abnormal performance of movement sequencing has been linked previously with anatomical changes of the brain [8-10], the traditional view of NSS pathogenesis stresses an inefficient cooperation between cortical and subcortical areas involved in complex motor functions [11]. The correct performance of a sequence of movements requires accurate timing of the execution of individual motor plans, which indicates the involvement of the cerebellum or cooperation between cortical and cerebellar areas [12]. Abnormal cortico-cerebellar connectivity would, therefore, lead to abnormalities of movement sequencing performance, as seen in schizophrenia. Functional brain connectivity in the context of movement sequencing abnormalities has not been analyzed before.

To test the hypothesis that abnormal functional connectivity between the motor cortex and cerebellum is linked with abnormal performance of movement sequencing rather than with the diagnosis of schizophrenia, we used a nontrivial sequential motor task during fMRI examination to activate the sensorimotor system of the brain in order to assess its functional connectivity and to analyze the correlates of cortico-cerebellar connectivity with the magnitude of motor sequencing abnormalities in patients with schizophrenia.

\section{Methods}

\section{Subjects}

We analyzed data from 24 schizophrenia patients and 24 age-, sex-, and handedness- (all subjects were right- handed) matched healthy controls. The diagnosis of schizophrenia was verified using the Mini-International Neuropsychiatric Interview (M.I.N.I.) [13]. All subjects were treated with atypical antipsychotics; the mean daily dose in chlorpromazine equivalents was $442 \mathrm{mg}$ (SD 286). Details of the demographic and clinical parameters are given in Table 1. The exclusion criteria were drug dependence (based on the M.I.N.I.; subjects with a history of drug abuse, but not dependence, were included), neurological or somatic conditions affecting the structure or function of the brain, and contraindications for MRI examination. Two schizophrenia patients were not able to undergo the MRI examination and were not included in subsequent analyses.

Healthy subjects were recruited from the community, local staff, and medical students. They were screened for Axis I psychiatric conditions using the M.I.N.I. Details of the demographic parameters are given in Table 1. The exclusion criteria were drug dependence, family history of Axis I psychiatric conditions, neurological or somatic conditions affecting the structure or function of the brain, and contraindications for MRI examination.

The study was approved by the local ethics committee (Ethical committee of the University Hospital Brno Bohunice) and all subjects signed an informed consent form.

\section{Behavioral examination}

All subjects were examined using the Neurological Evaluation Scale (NES) [14] to assess the expression of abnormal movement sequencing (NSS-SQ subscale; we also examined other domains-abnormalities of motor coordination NSS-MC subscale, and sensory integration NSS-SI subscale-to compare the relative frequencies of individual domains of neurological abnormalities in our sample). The ability to perform several movements in time-a sequencing of movements-was assessed using the "fist-ring test" (rapid alternation between clenching the fist and forming a ring using the thumb and forefinger), "fist-edge-palm test" (tapping the desk using the fist, edge of the hand, and palm of the hand), "rhythm tapping test" (reproduction of several rhythms), and the "Ozeretski test" (both hands are placed on the table, one palm down, one palm up, and the subject is asked to simultaneously alternate the position of the hands). All the tests are performed separately using both hands. The performance is rated on a three-point scale: "0" normal performance, " 1 " - mild impairment, " 2 " marked impairment. The final score of the "Mmovement sequencing domain" is a sum of all test ratings from both hands.

Handedness was also assessed using the NES scale-it is a performance-based evaluation- with hand dominance described as right, left, or mixed. 
Table 1 Demographic and behavioral characteristics

\begin{tabular}{|c|c|c|c|c|c|c|c|c|c|c|c|c|c|c|c|}
\hline Group & No. & $\begin{array}{l}\text { Age } \\
\text { (SD) }\end{array}$ & $\begin{array}{l}\text { Gender } \\
(\mathrm{M} / \mathrm{F})\end{array}$ & $\begin{array}{l}\text { Abuse } \\
\text { (\%) }\end{array}$ & $\begin{array}{l}\mathrm{FH}- \\
\mathrm{SCH} \\
(\%)\end{array}$ & $\begin{array}{l}\text { Education } \\
\mathrm{P} / \mathrm{S} / \mathrm{U}(\%)\end{array}$ & $\begin{array}{l}\text { Unemployment } \\
\text { (\%) }\end{array}$ & $\begin{array}{l}\text { Marital } \\
\text { status Si/Ma/ } \\
\text { Di } \\
(\%)\end{array}$ & $\begin{array}{l}\text { BAS } \\
(\%)\end{array}$ & $\begin{array}{l}\text { AIMS } \\
\text { (\%) }\end{array}$ & $\begin{array}{l}\text { SAS } \\
(\%)\end{array}$ & $\begin{array}{l}\text { NSS- } \\
\text { T (\%) }\end{array}$ & $\begin{array}{l}\mathrm{SI} \\
(\%)\end{array}$ & $\begin{array}{l}\text { MC } \\
(\%)\end{array}$ & $\begin{array}{l}\text { SQ } \\
(\%)\end{array}$ \\
\hline $\mathrm{HC}$ & 24 & $\begin{array}{l}31.8 \\
(9.2)\end{array}$ & $11 / 13$ & $0^{*}$ & 0 & $\begin{array}{l}1 / 12 / 11^{*} \\
(4.2 / 50 / 45.8)\end{array}$ & $2^{*}(8.3)$ & $\begin{array}{l}18 / 5 / 1(75 / \\
20.8 / 4.2)\end{array}$ & $0^{*}$ & 0 & $0^{* *}$ & $\begin{array}{l}1 * * \\
(4.2)\end{array}$ & $0^{*}$ & 0 & $\begin{array}{l}1 * * \\
(4.2)\end{array}$ \\
\hline $\mathrm{SCH}$ & 24 & $\begin{array}{l}32.8 \\
(9.7)\end{array}$ & $11 / 13$ & $5(21)$ & $\begin{array}{l}3 \\
(13.6)\end{array}$ & $\begin{array}{l}4 / 17 / 3 \\
(16.7 / 70.8 / \\
12.5)\end{array}$ & 16 (69.6) & $\begin{array}{l}16 / 4 / 3(69.6 / \\
17.4 / 13)\end{array}$ & $\begin{array}{l}5 \\
(20.8)\end{array}$ & 0 & $\begin{array}{l}15 \\
(62.5)\end{array}$ & $\begin{array}{l}21 \\
(87.5)\end{array}$ & $\begin{array}{l}8 \\
(33.3)\end{array}$ & $\begin{array}{l}3 \\
(12.5)\end{array}$ & $\begin{array}{l}16 \\
(66.7)\end{array}$ \\
\hline $\mathrm{SQ}+$ & 7 & $\begin{array}{l}36.9 \\
(6.6)\end{array}$ & $3 / 4$ & 0 & $\begin{array}{l}1 \\
(16.7)\end{array}$ & $\begin{array}{l}1 / 5 / 1(14.3 / \\
71.4 / 14.1)\end{array}$ & $6(85.7)$ & $\begin{array}{l}4 / 1 / 1(66.7 / \\
16.7 / 16.7)\end{array}$ & $\begin{array}{l}2 \\
(28.6)\end{array}$ & 0 & $\begin{array}{l}5 \\
(71.4)\end{array}$ & $\begin{array}{l}7 \\
(100)\end{array}$ & $\begin{array}{l}1 \\
(14.3)\end{array}$ & $\begin{array}{l}2 \\
(28.6)\end{array}$ & $\begin{array}{l}7^{*} \\
(100)\end{array}$ \\
\hline SQ- & 17 & $\begin{array}{l}31.1 \\
(10.4)\end{array}$ & $8 / 9$ & $5(29)$ & $\begin{array}{l}2 \\
(12.5)\end{array}$ & $\begin{array}{l}3 / 12 / 2 \\
(17.7 / 70.6 / \\
11.8)\end{array}$ & $10(62.5)$ & $\begin{array}{l}12 / 3 / 2(70.6 / \\
17.6 / 11.8)\end{array}$ & $\begin{array}{l}3 \\
(17.7)\end{array}$ & 0 & $\begin{array}{l}10 \\
(58.8)\end{array}$ & $\begin{array}{l}14 \\
(82.4)\end{array}$ & $\begin{array}{l}7 \\
(41.2)\end{array}$ & $\begin{array}{l}1 \\
(4.2)\end{array}$ & $\begin{array}{l}9 \\
(52.9)\end{array}$ \\
\hline
\end{tabular}

HC- healthy controls, SCH- schizophrenia patients, SQ + schizophrenia patients with marked movement sequencing abnormalities (SQ score > 2), SQschizophrenia patients without movement sequencing abnormalities; M- male, F- female; R- right, M- mixed, L- left; FH-SCH- family history of schizophrenia; Pprimary, S- secondary, U- university education; Si-single, Ma- married, Di- divorced; BAS- Barnes Akathisia Scale; AIMS- Abnormal Involuntary Movements Scale, SAS- Simpson-Angus Scale; NSS-T- neurological soft signs total score, SI- sensory integration, MC- motor coordination, SQ- movement sequencing. Frequencies of subjects with at least one mild impairment in NES are given here. ${ }^{*} \mathrm{p}<0.05,{ }^{* *} \mathrm{p}<0.001-$ significance level for group comparisons (HC vs. SCH, SQ + vs. SQ-)

The magnitude of extrapyramidal adverse effects of antipsychotic drugs was assessed using the Barnes Akathisia Scale (BAS), the Simpson-Angus Scale (SAS), and the Abnormal Involuntary Movement Scale (AIMS). These scales were used to check if the NSS were related to the medication effects, rather than to brain abnormalities.

\section{fMRI examination}

All subjects underwent functional MRI examination in a Philips Achieva $1.5 \mathrm{~T}$ scanner (FFE EPI sequence, 33 axial slices, $80 \times 80$, in-plane resolution $2.85 \times 2.85$ $\mathrm{mm}$, slice thickness $3.7 \mathrm{~mm}, \mathrm{TR}=3 \mathrm{~s}$, TE $50 \mathrm{~ms}$ ). The activation paradigm consisted of a sequential fingertapping task (repetitive tapping of the four fingers against a board), a finger opposition task (repetitive tapping of all fingers together against a board; included to evaluate if typical activation of cortico-cerebellar motor regions exists during a simple motor task), and a motor rest condition. The conditions were performed in $30 \mathrm{~s}$ blocks, and repeated 4 times (resulting in 120 images/time-points). Before entering the scanner, subjects were trained to perform the movements at around $2 \mathrm{~Hz}$. Subjects were visually monitored during the fMRI examination, and, if necessary, instructed through headphones.

\section{Image processing}

The fMRI images were processed using the SPM8 toolbox (http://www.fil.ion.ucl.ac.uk/spm). They were realigned, co-registered to a high-resolution structural image, normalized to the standard MNI space, and smoothed using an $8 \mathrm{~mm}$ FWHM Gaussian kernel. The data entered the General Linear Model (GLM) design at a single-subject level as follows: two regressors of interest were created for the sequential movement condition and the simple opposite movement condition. The movement and rotations estimated during the realignment step were used to create six additional regressors of no interest. Contrast images for the condition where sequential tapping elicited higher activation compared to the motor rest condition entered second level analysis-a full factorial design with a fixed factor group (schizophrenia patients, healthy subjects). This GLM design was used for a) analysis of group differences in brain activation during sequential motor tasks (significance threshold $\mathrm{p}<0.05$, FWE corrected), and b) for creating a whole-sample activation map during sequential motor tasks ( $\mathrm{p}<0.05$, FWE corrected). This whole-sample activation map was used to select coordinates in predefined seed regions for subsequent functional connectivity analysis (see Figure 1).

For the connectivity analysis, we extracted data from 5 $\mathrm{mm}$ spheres with centers at statistical local maxima in clusters in the left motor cortex MC (BA4, precentral gyrus, MNI oriae $3-1955$ ), the suplmnaymtrcre M B6 $\mathrm{N}$ oriae 3-10 58), and the right cerebellum CRBL (anterior lobe, culmen, MNI coordinates 12-55 -23) from all single-subject data. The data were filtered (high-pass filter, AR), and adjusted for the effect of interest (contrast sequencing > rest, i.e., all other effects, including head motion parameters and mean, were filtered from the data). Subsequently, the first eigenvariate of the seed region $B O L D$ time-course (i.e., the most typical representation of the time-course containing the largest part of the variability of the data) was extracted. The similarity of time-courses between individual seed regions was used as a measure of functional connectivity. To accomplish this, we performed a correlation analysis between the seed time-courses (MC-CRBL and SMA-CRBL) of every subject of the study. The significance of the correlations was tested using the one-sample $t$-test. 


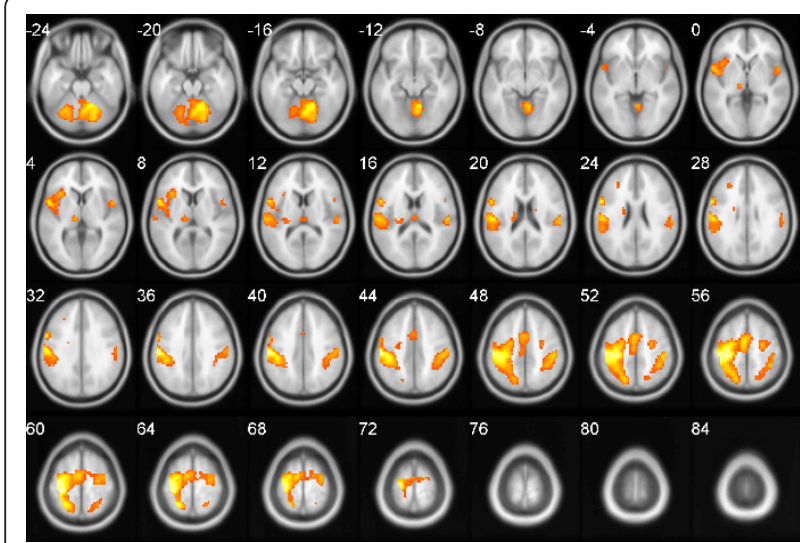

Figure 1 Brain activation during sequential finger-tapping task Positive effect of condition (sequential finger-tapping task vs. rest) on the whole group level ( $p<0.05$ FWE corrected). The left side of the brain is on the left side of the image. Note that there were no significant differences in the brain activation between schizophrenia patients and healthy controls, nor were there any differences between the two schizophrenia subgroups.

\section{Statistical analyses}

The normality of the distribution of functional connectivity measures was tested using Kolmogorov-Smirnov test. The distribution did not differ significantly from the normal distribution; therefore, we used parametric tests for subsequent statistical analysis.

Group differences in demographic, behavioral, and clinical variables were tested using two-sample t-tests or chi-square tests. The relationships between continuous demographic, behavioral, and clinical variables were tested using correlation analysis.

The effect of diagnosis on the functional connectivity measures was tested using the two-sample $t$-test. The effect of SQ abnormalities on the functional connectivity measures was tested using correlation analysis between the SQ score and MC-CRBL and SMA-CRBL. We divided the schizophrenia patients according to the presence of marked movement sequencing abnormalities into two subgroups: patients with at least one marked abnormality in any SQ subtest (patients with a SQ score higher than 2) formed a group with sequencing abnormalities (SQ+), patients with at most mild abnormality in any SQ subtests (a SQ score less than or equal to 2) formed a group without sequencing abnormalities (SQ-). We specified ANCOVA designs with functional connectivity measures as a dependent variable, group $(\mathrm{SQ}+$, SQ-, HC) as a categorical variable, and age as a continuous variable. The age parameter was included to account for the differences in age between the two patient subgroups and healthy controls group, since the age matching was performed only for the whole groups. After an omnibus test determined the significance of the effect of the group, we performed additional post-hoc least-significant-difference (LSD) testing of the withingroup differences. Finally, we analyzed the confounding effects of demographic and clinical variables on connectivity parameters. If there were any significant relationships between these variables, we performed an analysis of covariance with the categorical parameter group (SQ $+\times$ SQ-) and the continuous parameter (the confounding variable) to assess its effect on group differences in connectivity. The level of significance was set to $\mathrm{p}<$ 0.05 .

\section{Results}

\section{Demographic data}

There were no differences in age, gender, or marital status between the schizophrenia patients and healthy controls. Healthy controls had university education more frequently than schizophrenia patients (Chi-square 7.2, $\mathrm{p}<0.05)$. Patients were also more frequently unemployed (Chi-square 18.6, p < 0.001). There were no differences in gender, age, education, employment, or marital status between the SQ + and SQ- patient groups.

\section{Behavioral and clinical data}

Schizophrenia patients had higher frequencies of psychoactive drug abuse (1 patient with cannabis, 1 with alcohol, and 3 with polymorphic abuse including methamphetamine and cannabis) than healthy controls (Chi-square 5.4, $\mathrm{p}<0.05$ ). There was a trend toward a higher frequency of family history for schizophrenia in the schizophrenia group (Chi-square 3.5, p = 0.06). Schizophrenia patients had a positive BAS scale (Chi-square 5.6, $\mathrm{p}<0.05$ ) and SAS scale (Chi-square 21.8, $\mathrm{p}<0.001$ ) more often than healthy controls. Schizophrenia patients had significantly higher scores on the SAS scale $(t=47$ $<0.001)$. No study subject had a positive AIMS score. No significant differences were found for the BAS score. A significantly higher proportion of schizophrenia patients had at least one mild impairment on the NSS scale (Chi-square 33.6, $\mathrm{p}<0.001$ ), NSS-SI subscale (Chisquare 9.6, $\mathrm{p}<0.05$ ), and NSS-SQ subscale (Chi-square $22.6, \mathrm{p}<0.001)$. There was a trend for a higher proportion of schizophrenia patients with at least one mild impairment of the NSS-MC subscale (Chi-quare 3.2, $\mathrm{p}=$ 0.07). Schizophrenia patients also had a higher total NSS score $(\mathrm{t}=77 \mathrm{p}<0.001)$, NSS-SI score $(\mathrm{t}=31<$ $0.05)$, and NSS-SQ score $(\mathrm{t}=47<0.001)$.

$\mathrm{SQ}+$ patients experienced more psychotic episodes $(\mathrm{t}=$ $27<0.05)$ than SQ- patients. There were no differences in diagnosis, duration of illness, antipsychotic medication, prescription of antiparkinsonian medication, rate of psychoactive drug abuse, or family history of schizophrenia. There were no differences in antipsychotic daily dose in 
chlorpromazine equivalents between the two patient groups, nor were there any significant differences in the magnitude of the SAS, AIMS, and BAS scores. SQ + patients had at least one impairment on the NSS-SQ (Chi-square 4.9, $\mathrm{p}<0.05$ ) subscale more frequently than SQ-patients. There were no differences in the expression of at least one mild impairment on the NSS total scale or the NSS-MC and NSS-SI subscales between the two groups. SQ + patients had a higher total NSS score $(\mathrm{t}=$ $28<0.05)$, and NSS-SQ subscale $(t=70<0.001)$. For frequencies, means, and standard deviations of demographic and clinical data, see Tables 1 and 2 .

The NSS-SQ subscale did not correlate with the number of psychotic episodes, age, disease duration, or daily antipsychotic dose in chlorpromazine equivalents. There were also no significant correlations with BAS, AIMS, or SAS extrapyramidal scales. On the other hand, extrapyramidal symptoms measured using the SAS scale correlated significantly with the NSS-MC subscale $(R=0.47, \mathrm{p}<0.05)$.

\section{Functional connectivity}

Brain activation patterns during the sequential fingertapping task included sensorimotor cortical areas, prefrontal and cingular executive areas, the parietal and temporal supramodal cortex, thalamus, basal ganglia, and cerebellum; for details, see Figure 1 and Table 3. There were no significant differences in the activation pattern between schizophrenia patients and healthy controls, or between SQ + and SQ- patients.

The mean of individual subject correlations between $\mathrm{MC}$ and CRBL (mean $\mathrm{r}=0.23$, SD 0.16, $\mathrm{t}=9.9$, $\mathrm{p}<$ 0.001 ) and SMA and CRBL (mean $r=0.26$, SD 0.16, $t=$ 11.0, $\mathrm{p}<0.001$ ) BOLD signals differed significantly from zero in the whole sample. There was a significant negative correlation between MC-CRBL and SQ score $(\mathrm{r}=$ 03, $\mathrm{p}<0.05)$ and between SMA-CRBL and SQ score ( $\mathrm{r}$ $=03, \mathrm{p}<0.05)$. No other NSS subscales correlated with the functional connectivity measures.

There was no effect of diagnosis on the functional connectivity measures: the whole group of schizophrenia patients did not differ from healthy controls. In the ANCOVA design there was a significant effect of SQ on the MC-CRBL functional connectivity measure $(\mathrm{F}=3.4$, $\mathrm{p}<0.05)$. LSD post-hoc testing revealed significant differences between SQ + and SQ-patients and SQ + patients and healthy controls: $\mathrm{SQ}+$ patients had a lower magnitude of MC-CRBL correlations than both groups. No differences were present between SQ- patients and healthy controls (Figure 2). There was no significant effect on SMA-CRBL functional connectivity measures.

Confounding effects: we found significant negative correlations between MC-CRBL and duration of illness $(R=03, p<0.05)$. When using this variable as a covariate in a subsequent ANCOVA model with connectivity parameters as the dependent variable, there was still a significant effect of the SQ group on MC-CRBL ( $F=$ $7.2, \mathrm{p}<0.05)$. There was no effect of education on the magnitude of MC-CRBL and SMA-CRBL correlations (see the group differences in education between $\mathrm{SCH}$ and $\mathrm{NC}$ ). There were also no significant correlations between daily antipsychotic dose (in chlorpromazine equivalents), MC-CRBL, and SMA-CRBL.

\section{Discussion}

We found a significant effect of movement sequencing abnormalities on the functional connectivity between the motor cortex and cerebellum during the execution of sequential motor tasks in schizophrenia. We found a significant negative correlation between the magnitudes of movement sequencing abnormalities measured using the NES scale and the level of cortico-cerebellar connectivity: the more pronounced the motor abnormality, the less similar the BOLD signal between cortical and cerebellar regions. Only patients with impaired movement sequencing abilities had lower functional connectivity than healthy controls (in contrast to patients with unimpaired movement sequencing). This means that abnormal cooperation between the cerebellum and motor cortex during a motor task manifests as an impaired ability to sequence movements in time.

Table 2 Clinical characteristics

\begin{tabular}{|c|c|c|c|c|c|c|c|c|c|c|c|c|}
\hline Group & $\begin{array}{l}\text { Dg. SCH/SAF } \\
\text { (\%) }\end{array}$ & Duration & Episodes & Dose & $\begin{array}{l}\text { AP MARTA/SDA } \\
\text { (\%) }\end{array}$ & BAS & AIMS & SAS & $\begin{array}{l}\text { AntiPark } \\
(\%)\end{array}$ & NSS-T & SI & MC \\
\hline $\mathrm{SCH}$ & $21 / 3(87.5 / 12.5)$ & $9.2(7.6)$ & $4.2(2.0)$ & $\begin{array}{l}364.5 \\
(203.1)\end{array}$ & $13 / 11(54.2 / 45.8)$ & $\begin{array}{l}0.7 \\
(1.9)\end{array}$ & 0 & $\begin{array}{l}1.2 \\
(1.3)\end{array}$ & $3(12.5)$ & $4.0(2.4)$ & $\begin{array}{l}0.9 \\
(1.4)\end{array}$ & $0.2(0.5)$ \\
\hline SQ+ & $5 / 2(71.4 / 28.6)$ & $13.8(7.2)$ & $5.7(1.3)^{*}$ & $\begin{array}{l}360.6 \\
(195.8)\end{array}$ & 4/3(57.1/42.9) & $\begin{array}{l}0.6 \\
(1.1)\end{array}$ & 0 & $\begin{array}{l}1.7 \\
(1.5)\end{array}$ & $1(14.3)$ & $\begin{array}{l}5.9^{*} \\
(2.2)\end{array}$ & $\begin{array}{l}0.3 \\
(0.8)\end{array}$ & $0.4(0.8)$ \\
\hline SQ- & $16 / 1(94.1 / 5.9)$ & $7.8(7.4)$ & 3.6(1.9) & $\begin{array}{l}366.1 \\
(212.0)\end{array}$ & $9 / 8(52.9 / 47.1)$ & $\begin{array}{l}0.7 \\
(2.2)\end{array}$ & 0 & $\begin{array}{l}1.0 \\
(1.1)\end{array}$ & $2(11.8)$ & $3.2(2.1)$ & $\begin{array}{l}1.1 \\
(1.5)\end{array}$ & $\begin{array}{l}0.06 \\
(0.2)\end{array}$ \\
\hline
\end{tabular}

SCH- schizophrenia patients, SQ + schizophrenia patients with marked movement sequencing abnormalities (SQ score > 2), SQ- schizophrenia patients without movement sequencing abnormalities; SCH- schizophrenia, SAF- schizoaffective disorder; AP- antipsychotic medication, MARTA- multi-acting receptor-targeted antipsychotics, SDA- serotonin-dopamine antagonists; BAS- Barnes Akathisia Scale; AIMS- Abnormal Involuntary Movements Scale, SAS- Simpson-Angus Scale; AntiPark- antiparkinsonian medication; NSS-T- neurological soft signs total score, SI- sensory integration, MC- motor coordination, SQ- movements sequencing. * $\mathrm{p}<0.05,{ }^{* *} \mathrm{p}<0.001$ - significance level for group comparisons (SQ + vs. SQ-) 
Table 3 Brain activation during sequential finger-tapping task

\begin{tabular}{|c|c|c|c|}
\hline Area & Brodmann Area & $\begin{array}{l}\text { volume (cc) } \\
\text { L/R }\end{array}$ & random effects: Max Value $(x, y, z)$ \\
\hline Precentral Gyrus & $3,4,6,44$ & $12.8 / 3.1$ & $14.5(-0-24,55) / 8.2(30,-10,62)$ \\
\hline Postcentral Gyrus & $1,2,3,5,7,40,43$ & $12.3 / 6.9$ & $13.6(-3-19,38) / 9.2(45,-28,47)$ \\
\hline Paracentral Lobule & 31 & $0.4 / 0.0$ & $6.4(-,-19,46) /-999.0(0,0,0)$ \\
\hline Superior Frontal Gyrus & 6 & $1.7 / 1.1$ & $9.1(-7-9,65) / 7.9(15,-4,65)$ \\
\hline Middle Frontal Gyrus & 6 & $4.4 / 2.8$ & $10.7(-7-7,57) / 8.1(24,-7,51)$ \\
\hline Inferior Frontal Gyrus & $9,44,45,47$ & $2.4 / 0.1$ & $9.9(-56,6,25) / 5.6(53,6,25)$ \\
\hline Medial Frontal Gyrus & 6,32 & $6.1 / 2.6$ & $9.8(-6,-4,54) / 8.0(3,4,50)$ \\
\hline Cingulate Gyrus & 24,32 & $1.3 / 0.7$ & $7.9(-3,4,45 / .3,4)$ \\
\hline Insula & 13,40 & $5.2 / 0.8$ & $8.7(-48,-23,19) / 7.1(50,-23,19)$ \\
\hline Superior Temporal Gyrus & $22,41,42$ & $3.3 / 1.0$ & $8.2(-50,2,1) / 6.9(50,8,1)$ \\
\hline Transverse Temporal Gyrus & 41,42 & $1.4 / 0.3$ & $7.8(-56,-18,13) / 6.9(53,-21,13)$ \\
\hline Superior Parietal Lobule & 5,7 & $3.5 / 0.9$ & $10.5(-21,-50,61) / 7.1(24,-50,59)$ \\
\hline Inferior Parietal Lobule & 2,40 & $9.6 / 5.2$ & $11.2(-42,-31,47) / 8.2(48,-28,44)$ \\
\hline Supramarginal Gyrus & 40 & $0.5 / 0.0$ & $7.4(-42,-37,36) /-999.0(0,0,0)$ \\
\hline Precuneus & 7 & $3.6 / 0.9$ & $8.6(-18,-60,51) / 6.3(18,-59,54)$ \\
\hline Lingual Gyrus & 18 & $0.1 / 0.3$ & $5.8(-12,-83,-13) / 6.9(18,-77,-10)$ \\
\hline Fusiform Gyrus & 19 & $0.1 / 0.0$ & $5.7(-21,-80,-13) /-999.0(0,0,0)$ \\
\hline Lentiform Nucleus & * & $0.1 / 0.0$ & $5.2(-30,-21,5) /-999.0(0,0,0)$ \\
\hline Claustrum & * & $0.1 / 0.0$ & $5.8(-27,14,9) /-999.0(0,0,0)$ \\
\hline Thalamus & * & $1.3 / 0.2$ & $7.3(-12,-21,5) / 5.7(6,-21,13)$ \\
\hline Declive & * & $6.1 / 6.6$ & $10.0(-27,-60,-19) / 10.9(12,-54,-12)$ \\
\hline Culmen & * & $2.6 / 4.7$ & $9.1(-24,-57,-19) / 10.4(9,-54,-9)$ \\
\hline Culmen of Vermis & * & $0.2 / 0.1$ & $8.8(0,-65,-8) / 9.3(3,-63,-9)$ \\
\hline Declive of Vermis & * & $0.4 / 0.5$ & $8.4(0,-69,-11) / 8.3(3,-69,-13)$ \\
\hline Cerebellar Lingual & * & $0.3 / 0.7$ & $5.6(-3,-45,-12) / 6.9(9,-48,-14)$ \\
\hline
\end{tabular}

Several findings support the significance of corticoeeelrfntoa dsoncin'fr various signs and symptoms of schizophrenia. Wilson et al. found right cerebellar dysfunction in a MEG study that analyzed cortico-cerebellar functional connectivity during tactile stimulation of the fingers that resulted in synchronous activation of the postcentral cortex and cerebellum in early onset psychosis [15]. Impaired functional connectivity between the cerebellum and the medial part of the superior frontal gyrus was observed during attentional tasks in schizophrenia [16]. Abnormal functional connectivity between the medial prefrontal cortex and the contralateral cerebellum was also found during the Hayling Sentence Completion Test in a high-risk sample [17], and in children and adolescents with schizophrenia during verbal working-memory tasks [18]. There are reports of abnormal functional connectivity between the cerebellum and cortex even at rest: parameters of resting state functional connectivity between the frontal cortex and cerebellum had the biggest discriminative value from a set of several regions for classification of schizophrenia patients and healthy controls [19]. Structural equation modeling allowed the analysis of the connectivity parameters between individual nodes of a network formed by the prefrontal cortex, thalamus, and cerebellum during an n-back working-memory task in schizophrenia: patients showed decreased cortico-cerebellar and thalamo-cerebellar functional connectivity, but increased thalamo-cortical functional connectivity [20].

Impaired functional cortico-cerebellar connectivity might result from abnormalities of some node of the cortico-subcortico-cerebellar circuits. However, several lines of evidence indicate that cerebellar dysfunction might have a key role in cortico-cerebellar dysconnection' and corresponding signs and symptoms, including movement sequencing abnormalities. Transcranial magnetic stimulation (TMS) data show that cerebellar activation or inhibition has a direct impact on the functioning of the motor cortex [21]. This finding, with the theoretical implications of the involvement of cerebellum in the pathogenesis of schizophrenia, provides further support for the validity of the regions we selected for functional connectivity analysis. Furthermore, there is evidence that sequence processing is one of the key functions of the cerebellum [12]. There are many findings that show cerebellar abnormalities in schizophrenia. Cerebellar inhibition of the motor cortex assessed by TMS is decreased in schizophrenia [22]. 


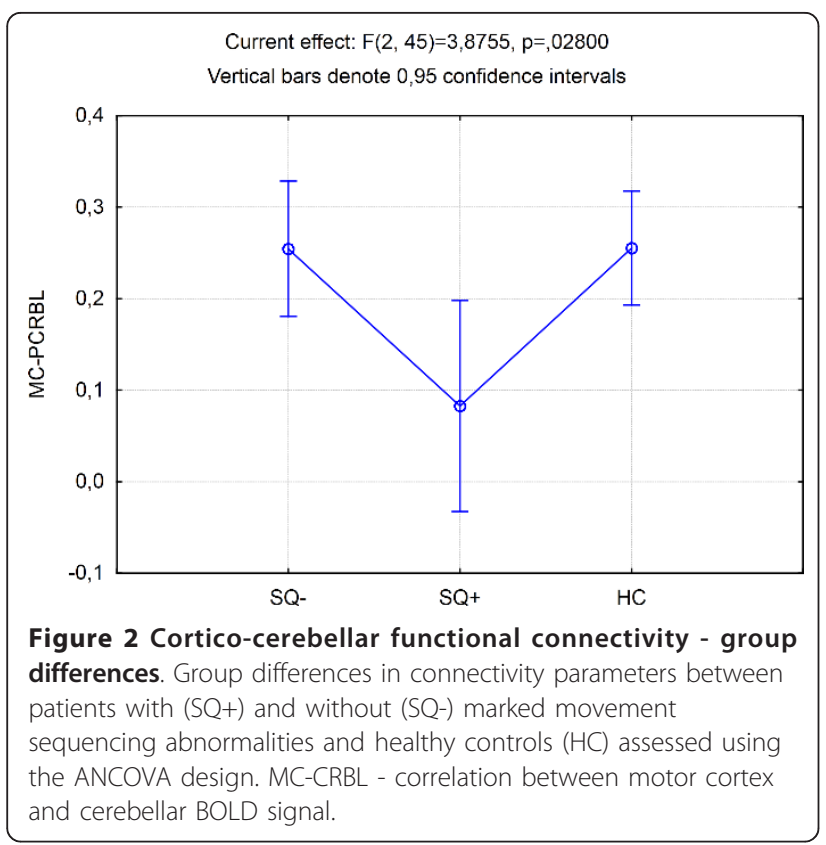

Reduction of cerebellar-dependent delay eyeblink conditioning [23] reflects impaired cerebellar time processing in schizophrenia. Cerebellar morphological changes are present in schizophrenia [24]; they are linked with NSS [25-27], including repetitive motor acts, i.e., sequences of movements $[25,28,29]$. Cerebellar abnormalities are linked to non-motor symptoms of schizophrenia, such as cognitive dysfunction [16,30,31]. Changes in cerebellar tract integrity that correlate with cognitive dysfunction [32] have been described in schizophrenia [33-35].

We were not able to find any effect of movement sequencing abnormalities on the pattern or magnitude of brain activation during the modified finger-tapping task. A previous fMRI study, using a similar behavioral paradigm, found reduced activation of the pallidum and putamen [36]. Our data show that impaired movement sequencing abilities are linked with brain connectivity, rather than with the magnitude of regional activation, which points to the original concept of NSS as a consequence of impaired cooperation between system subcomponents, and not a single localized pathology [11]. On the other hand, the lack of group differences in brain activation patterns may also reflect an inadequate behavioral paradigm for movement sequencing examination. Although the principle behind the modified sequential finger-tapping task is similar to the NES scale sequencing tasks, the tasks are not identical and may require different effort for their execution and reflect different brain loads. Our paradigm was, however, adequate for the analysis of brain connectivity in the context of movement sequences, which was the primary focus of our study.
The impaired ability to sequence movements was the most frequent movement abnormality in schizophrenia patients: $67 \%$ of the patients had at least one mild impairment of movement sequencing as compared to a $33 \%$ incidence of sensory integration problems, and 13\% of motor coordination abnormalities. The pattern and incidence of individual NSS categories are in accordance with previous findings [1]. The relative predominance of movement sequencing abnormalities in schizophrenia might reflect its link to a proposed neurobiological substrate of the illness-brain 'dysconnection'.

Patients with marked movement sequencing impairment had more psychotic episodes than those without movement sequencing disturbances. Moreover, corticocerebellar functional connectivity correlated negatively with the duration of treatment. These findings may mean that there is a progressive worsening of corticocerebellar connectivity with a corresponding impairment of movement sequencing as a result of consecutive psychotic outbreaks. Our study was, however, a cross-sectional comparison. Therefore, we cannot exclude the possibility that patients with marked impairments of movement sequencing abnormalities had such marked impairment present from the beginning of the illness. Previous studies show that the expression of NSS at the time of the first episode of schizophrenia predicts a worse response to treatment and worse outcomes [37-39]. Abnormalities of cerebellar morphology are also linked with poor outcomes [40]. The fact that there was a still a significant effect of movement sequencing abnormalities present in the post-hoc analysis of covariance suggests that movement sequencing abnormalities and their link to cortico-cerebellar connectivity are not only the result of illness progression.

Several factors might limit our results. The most important are the effects of antipsychotics, extrapyramidal symptoms, and abuse of psychoactive substances. The severity of movement sequencing abnormalities does not correlate with antipsychotic treatment parameters, nor with the severity of extrapyramidal symptoms. Similarly, the differences in cortico-cerebellar connectivity between the two patient groups are not a result of antipsychotic treatment or extrapyramidal symptoms. This is supported by previous findings $[2,3]$. These factors are, however, linked significantly with the other NSS cluster-movement coordination abnormalities-which may reflect different neurobiology and etiology of individual movement abnormalities in schizophrenia. Findings have shown a relationship between the severity of cerebellar impairment and comorbid alcohol abuse in schizophrenia [41]. In our study, however, there were no differences in co-morbid psychoactive substance abuse between the two patient groups. Finally, we assessed only the functional 
connectivity related to movement sequencing. But the cerebellum is involved in several other functions, including cognitive and affective ones [42]. Based on our study, we cannot exclude the possibility that there is a functional dysconnection of different parts of the cortex and cerebellum during the cerebellar functions other than movement sequencing in SQ- patients.

\section{Conclusion}

Abnormal cortico-cerebellar functional connectivity during the performance of a motor task is linked with movement sequencing abnormalities in schizophrenia, but not with the diagnosis of schizophrenia per se. It seems that specific patterns of interregional connectivity are linked with corresponding signs and symptoms of clinically heterogeneous conditions such as schizophrenia.

\section{Acknowledgements}

The study was supported by research grant No. NR9855-4 provided by the Ministry of Health, Youth, and Sports of the Czech Republic and by the project "CEITEC - Central European Institute of Technology" (CZ.1.05/1.1.00/ 02.0068) from the European Regional Development Fund.

\section{Author details \\ ${ }^{1}$ Department of Psychiatry, University Hospital Brno and Masaryk University, Jihlavska 20, 62500 Brno, Czech Republic. ²Behavioral and Social Neuroscience Research Group, CEITEC - Central European Institute of Technology, Masaryk University, Kamenice 5, 62500 Brno, Czech Republic. ${ }^{3}$ Department of Radiology, University Hospital Brno and Masaryk University, Jihlavska 20, 62500 Brno, Czech Republic. ${ }^{4}$ Molecular and Functional Neuroimaging Research Group, CEITEC - Central European Institute of Technology, Masaryk University, Kamenice 5, 62500 Brno, Czech Republic.}

\section{Authors' contributions}

Author Tomas Kasparek designed the study, wrote the protocol, undertook the data analysis, and wrote the first draft of the manuscript. Author Jitka Rehulova managed the literature searches and contributed to data collection and preparation. Author Milos Kerkovsky contributed to the design of the study and its protocol. Authors Andrea Sprlakova and Marek Mechl were responsible for clinical interpretation and preprocessing of the MRI data. Author Michal Mikl contributed to the connectivity analysis. All authors contributed to and have approved the final manuscript.

\section{Competing interests}

The authors declare that they have no competing interests.

Received: 2 November 2011 Accepted: 12 March 2012 Published: 12 March 2012

\section{References}

1. Bombin I, Arango C, Buchanan RW: Significance and meaning of neurological signs in schizophrenia: two decades later. Schizophr Bull 2005, 31(4):962-977.

2. Wolff AL, O'Driscoll GA: Motor deficits and schizophrenia: the evidence from neuroleptic-naive patients and populations at risk. J Psychiatry Neurosci 1999, 24(4):304-314

3. Whitty PF, Owoeye O, Waddington JL: Neurological Signs and Involuntary Movements in Schizophrenia: Intrinsic To and Informative on Systems Pathobiology. Schizophr Bull 2009, 35(2):415-424

4. Friston KJ, Frith CD: Schizophrenia: a disconnection syndrome? Clin Neurosci 1995, 3(2):89-97.
5. Andreasen NC, Paradiso S, O'Leary DS: "Cognitive dysmetria" as an integrative theory of schizophrenia: a dysfunction in cortical-subcorticalcerebellar circuitry? Schizophr Bull 1998, 24(2):203-218.

6. Repovs G, Csernansky JG, Barch DM: Brain network connectivity in individuals with schizophrenia and their siblings. Biol Psychiatry 2011, 69(10):967-973.

7. Calhoun VD, Eichele T, Pearlson G: Functional brain networks in schizophrenia: a review. Front Hum Neurosci 2009, 3:17.

8. Kasparek T, Prikryl R, Schwarz D, Tronerova S, Ceskova E, Mikl M, Vanicek J: Movement sequencing abilities and basal ganglia morphology in firstepisode schizophrenia. World J Biol Psychiatry 2009, 10 (4 Pt 3):752-762.

9. Dazzan P, Morgan KD, Orr KG, Hutchinson G, Chitnis X, Suckling J, Fearon P, Salvo J, McGuire PK, Mallett RM, et al: The structural brain correlates of neurological soft signs in AESOP first-episode psychoses study. Brain 2004, 127(Pt 1):143-153.

10. Thomann PA, Wustenberg T, Santos VD, Bachmann S, Essig M, Schroder J. Neurological soft signs and brain morphology in first-episode schizophrenia. Psychol Med 2009, 39(3):371-379.

11. Heinrichs DW, Buchanan RW: Significance and meaning of neurological signs in schizophrenia. Am J Psychiatry 1988, 145(1):11-18.

12. Molinari M, Chiricozzi FR, Clausi S, Tedesco AM, De Lisa M, Leggio MG: Cerebellum and detection of sequences, from perception to cognition. Cerebellum 2008, 7(4):611-615.

13. Sheehan DV, Lecrubier $Y$, Sheehan $K H$, Amorim $P$, Janavs J, Weiller $E$, Hergueta T, Baker R, Dunbar GC: The Mini-International Neuropsychiatric Interview (M.I.N.I.): the development and validation of a structured diagnostic psychiatric interview for DSM-IV and ICD-10. J Clin Psychiatry 1998, 59(20):22-33, quiz 34-57.

14. Buchanan RW, Heinrichs DW: The Neurological Evaluation Scale (NES): a structured instrument for the assessment of neurological signs in schizophrenia. Psychiatry Res 1989, 27(3):335-350.

15. Wilson TW, Slason E, Hernandez OO, Asherin R, Reite ML, Teale PD, Rojas DC: Aberrant high-frequency desynchronization of cerebellar cortices in early-onset psychosis. Psychiatry Res 2009, 174(1):47-56.

16. Honey GD, Pomarol-Clotet E, Corlett PR, Honey RA, McKenna PJ, Bullmore ET, Fletcher PC: Functional dysconnectivity in schizophrenia associated with attentional modulation of motor function. Brain 2005, 128(Pt 11):2597-2611.

17. Whalley HC, Simonotto E, Marshall I, Owens DG, Goddard NH, Johnstone EC, Lawrie SM: Functional disconnectivity in subjects at high genetic risk of schizophrenia. Brain 2005, 128(Pt 9):2097-2108.

18. White T, Schmidt M, Kim DI, Calhoun VD: Disrupted Functional Brain Connectivity during Verbal Working Memory in Children and Adolescents with Schizophrenia. Cereb Cortex 2011, 21(3):510-518.

19. Shen $H$, Wang $L, L i u ~ Y, H u$ D: Discriminative analysis of resting-state functional connectivity patterns of schizophrenia using low dimensional embedding of fMRI. Neuroimage 2010, 49(4):3110-3121.

20. Schlosser R, Gesierich T, Kaufmann B, Vucurevic G, Hunsche S, Gawehn J, Stoeter $\mathrm{P}$ : Altered effective connectivity during working memory performance in schizophrenia: a study with $\mathrm{fMRI}$ and structural equation modeling. Neuroimage 2003, 19(3):751-763.

21. Daskalakis ZJ, Paradiso GO, Christensen BK, Fitzgerald PB, Gunraj C, Chen R: Exploring the connectivity between the cerebellum and motor cortex in humans. J Physiol 2004, 557:689-700.

22. Daskalakis ZJ, Christensen BK, Fitzgerald PB, Fountain SI, Chen R: Reduced cerebellar inhibition in schizophrenia: a preliminary study. Am J Psychiatry 2005, 162(6):1203-1205.

23. Bolbecker AR, Mehta CS, Edwards CR, Steinmetz JE, O'Donnell BF, Hetrick WP: Eye-blink conditioning deficits indicate temporal processing abnormalities in schizophrenia. Schizophrenia Research 2009, 111(13):182-191.

24. Nopoulos PC, Ceilley JW, Gailis EA, Andreasen NC: An MRI study of cerebellar vermis morphology in patients with schizophrenia: evidence in support of the cognitive dysmetria concept. Biol Psychiatry 1999, 46(5):703-711.

25. Bersani G, Paolemili M, Quartini A, Clemente R, Gherardelli S, lannitelli A, Di Biasi C, Gualdi G, Pancheri P: Neurological soft signs and cerebral measurements investigated by means of MRI in schizophrenic patients. Neurosci Lett 2007, 413(1):82-87. 
26. Bottmer C, Bachmann S, Pantel J, Essig M, Amann M, Schad LR, Magnotta V, Schroder J: Reduced cerebellar volume and neurological soft signs in first-episode schizophrenia. Psychiatry Res 2005, 140(3):239-250.

27. Thomann PA, Roebel M, Dos Santos V, Bachmann S, Essig M, Schroder J: Cerebellar substructures and neurological soft signs in first-episode schizophrenia. Psychiatry Res 2009, 173(2):83-87.

28. Keshavan MS, Sanders RD, Sweeney JA, Diwadkar VA, Goldstein G, Pettegrew JW, Schooler NR: Diagnostic specificity and neuroanatomical validity of neurological abnormalities in first-episode psychoses. Am J Psychiatry 2003, 160(7):1298-1304.

29. Venkatasubramanian G, Jayakumar PN, Gangadhar BN, Keshavan MS: Neuroanatomical correlates of neurological soft signs in antipsychoticnaive schizophrenia. Psychiatry Res 2008, 164(3):215-222.

30. Laywer G, Nyman H, Agartz I, Arnborg S, Jonsson EG, Sedvall GC, Hall H: Morphological correlates to cognitive dysfunction in schizophrenia as studied with Bayesian regression. BMC Psychiatry 2006, 6:31.

31. Segarra N, Bernardo M, Valdes M, Caldu X, Falcon C, Rami L, Bargallo N, Parramon $G$, Junque $C$ : Cerebellar deficits in schizophrenia are associated with executive dysfunction. Neuroreport 2008, 19(15):1513-1517.

32. Okugawa G, Nobuhara K, Minami T, Takase K, Sugimoto T, Saito $Y$ Yoshimura M, Kinoshita T: Neural disorganization in the superior cerebellar peduncle and cognitive abnormality in patients with schizophrenia: A diffusion tensor imaging study. Prog Neuropsychopharmacol Biol Psychiatry 2006, 30(8):1408-1412.

33. Kanaan RA, Borgwardt S, McGuire PK, Craig MC, Murphy DG, Picchioni M, Shergill SS, Jones DK, Catani M: Microstructural organization of cerebellar tracts in schizophrenia. Biol Psychiatry 2009, 66(11):1067-1069.

34. Magnotta VA, Adix ML, Caprahan A, Lim K, Gollub R, Andreasen NC: Investigating connectivity between the cerebellum and thalamus in schizophrenia using diffusion tensor tractography: a pilot study. Psychiatry Res 2008, 163(3):193-200.

35. Okugawa G, Nobuhara K, Sugimoto T, Kinoshita T: Diffusion tensor imaging study of the middle cerebellar peduncles in patients with schizophrenia. Cerebellum 2005, 4(2):123-127.

36. Menon V, Anagnoson RT, Glover GH, Pfefferbaum A: Functional magnetic resonance imaging evidence for disrupted basal ganglia function in schizophrenia. Am J Psychiatry 2001, 158(4):646-649.

37. Prikryl R, Ceskova E, Kasparek T, Kucerova H: Neurological soft signs and their relationship to 1-year outcome in first-episode schizophrenia. Eur Psychiatry 2007, 22(8):499-504.

38. Prikryl R, Ceskova E, Kasparek T, Kucerova H: Neurological soft signs, clinical symptoms and treatment reactivity in patients suffering from first episode schizophrenia. J Psychiatr Res 2006, 40(2):141-146.

39. Das M, Kumari V, Soni W, Ettinger U, Binneman B, Hughes C, Mehrotra R, Sharma T: Neurological soft signs and their relationship to cognitive and clinical efficacy of atypical antipsychotics in schizophrenia. Schizophr Bull 2004, 30(2):241-253.

40. Wassink TH, Andreasen NC, Nopoulos P, Flaum M: Cerebellar morphology as a predictor of symptom and psychosocial outcome in schizophrenia. Biol Psychiatry 1999, 45(1):41-48.

41. Sullivan EV, Deshmukh A, Desmond JE, Mathalon DH, Rosenbloom MJ, Lim KO, Pfefferbaum A: Contribution of alcohol abuse to cerebellar volume deficits in men with schizophrenia. Arch Gen Psychiatry 2000, 57(9):894-902.

42. Katz DB, Steinmetz JE: Psychological functions of the cerebellum. Behav Cogn Neurosci Rev 2002, 1(3):229-241.

\section{Pre-publication history}

The pre-publication history for this paper can be accessed here: http://www.biomedcentral.com/1471-244X/12/17/prepub

doi:10.1186/1471-244X-12-17

Cite this article as: Kasparek et al:: Cortico-cerebellar functional connectivity and sequencing of movements in schizophrenia. BMC Psychiatry 2012 12:17.

\section{Submit your next manuscript to BioMed Central and take full advantage of:}

- Convenient online submission

- Thorough peer review

- No space constraints or color figure charges

- Immediate publication on acceptance

- Inclusion in PubMed, CAS, Scopus and Google Scholar

- Research which is freely available for redistribution

Submit your manuscript at www.biomedcentral.com/submit 